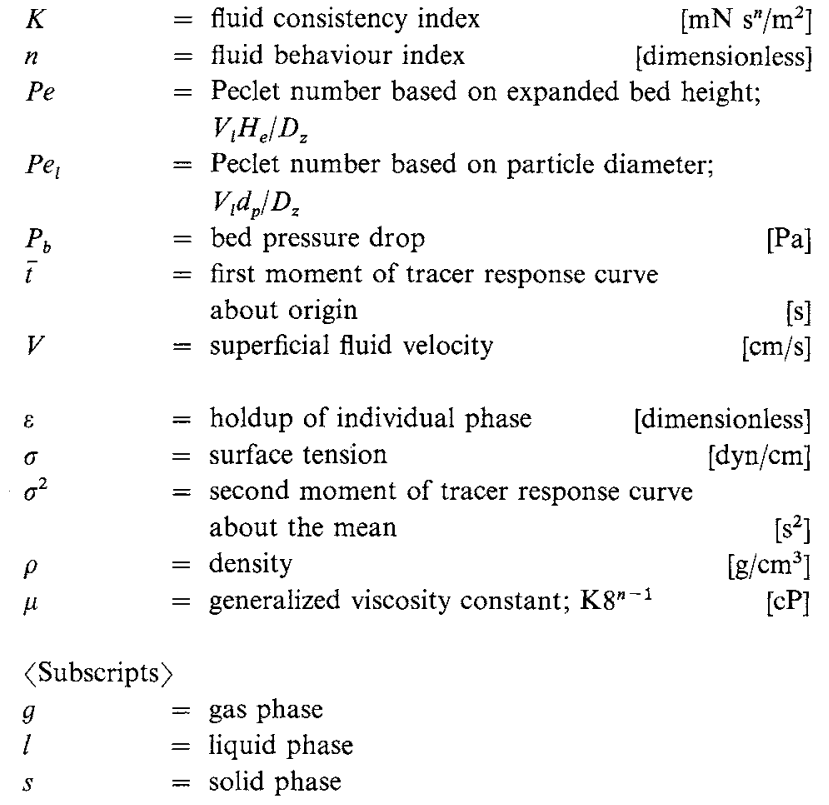

\section{Literature Cited}

1) Afschar, A. A. and K. Schügerl: Chem. Eng. Sci., 23, 267 (1968).

2) Baird, M. H. I. and R. G. Rice: Chem. Eng. J, 9, 171 (1975).

3) Bischoff, K. B. and O. Levenspiel: Chem. Eng. Sci., 17, 257 (1962).

4) Eissa, S. H. and K. Schügerl: Chem. Eng. Sci., 30, 1251 (1975).
5) El-Temtamy, S. A., Y. D. El-Sharnoubi and M. M. ElHalwagi: Chem. Eng. J., 18, 151 (1979).

6) Epstein, N.: Can. J. Chem. Eng., 59, 649 (1981).

7) Hikita, H. and H. Kikukawa: Chem. Eng. J., 8, 191 (1974).

8) Joshi, J. B.: Trans. Chem. E., 58, 155 (1980).

9) Kim, S. D. and C. H. Kim: Hwahak Konghak, 18, 313 (1980).

10) Kim, S. D., C. G. J. Baker and M. A. Bergougnou: Can. J. Chem. Eng., 50, 695 (1972).

11) Kim, S. D., C. G. J. Baker and M. A. Bergougnou: Can. J. Chem. Eng., 53, 134 (1975).

12) Kim, S. D., C. G. J. Baker and M. A. Bergougnou: Chem. Eng. Sci., 32, 1299 (1977)

13) Levenspiel, O. and K. B. Bischoff: Adv. Chem. Eng., 4, 95 (1963).

14) Letan; R. and J. C. Elgin: Chem. Eng. J., 3, 136 (1972).

15) Michelsen, M. L. and K. Østergaard: Chem. Eng. J., 1, 37 (1970).

16) Muroyama, K., K. Hashimoto, T. Kawabata and M. Shiota: Kagaku Kogaku Rorbunshu, 4, 622 (1978).

17) Oki, Y. and H. Inoue: Chem. Eng. Sci., 25, 1 (1970).

18) Østergaard, K.: Adv. Chem. Eng., 7, 71 (1968).

19) Østergaard, K. and M. L. Michelsen: Symp. Fund. Appl. Fluidization, Tampa, Florida, May (1968).

20) Østergaard, K.: "Fluidization," ed. by Davidson and Harrison, p. 753, Academic Press, New York (1971).

21) Østergaard, K.: AIChE Symp. Ser., 74(176), 82 (1978).

22) Savinsky, J., J. Hunek and L. Podmaniczky: Int. Chem. Eng., 20, $681(1980)$.

23) Schügerl, K.: Int. Symp. on Fluidization, p. 782 (1967).

24) Vail, $\mathrm{Yu}, \mathrm{K}$., N. Kh. Manakov and V. V. Manshilin: Int. Chem. Eng., 8, 293 (1968).

25) Van der Laan, E. T.: Chem. Eng. Sci., 7, 187 (1957).

\title{
GAS-PARTICLE HEAT TRANSFER IN A DISPERSED BED
}

\author{
KUNIO KATO, ICHIRO ONOZAWA AND YOSHIKAZU NOGUCHI \\ Department of Chemical Engineering, Gunma University, Kiryu 376
}

\begin{abstract}
Wet activated alumina particles were dried in the constant drying rate period in a dispersed bed. The heat transfer coefficients between the particles and gas were measured.

The Nusselt number for gas-particle heat transfer in the dispersed bed was affected by the particle Reynolds number and the void fraction. The empirical equation for gas-particle heat transfer in the dispersed bed was obtained.
\end{abstract}

\section{Introduction}

The estimation of gas-particle heat transfer coefficient is very important in the design and analysis of various kinds of processes accompanied by heat transfer, such as drying, adsorption, combustion and catalytic reaction.

Ranz and Marshall ${ }^{1)}$ obtained the empirical equa-

Received June 25, 1982. Correspondence concerning this article should be addressed to $\mathrm{K}$. Kato. I. Onozawa is now with Shinetsu Chemical Co. Ltd., Isobe, Gunma. tion for heat or mass transfer coefficient from a single particle in fluid. The Nusselt number converges to 2 as the particle Reynolds number becomes very small. Ranz and Marshall's equation is usually used to estimate the gas-particle heat transfer coefficient in the pneumatic conveying dryer, in the case of high Reynolds number $(R e \geqq 100)$. However, there is no suitable empirical equation to estimate the heat transfer coefficient in the case of low particle Reynolds number. 


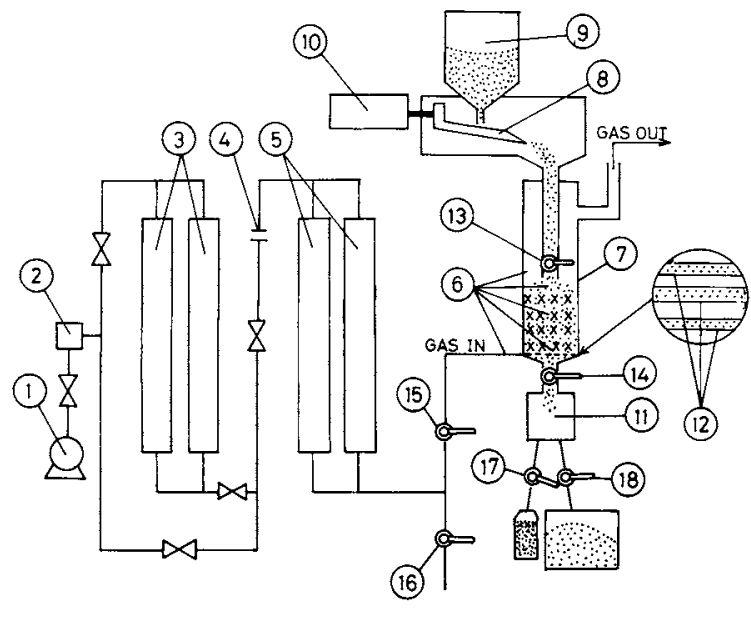

Fig. 1. Experimental apparatus.

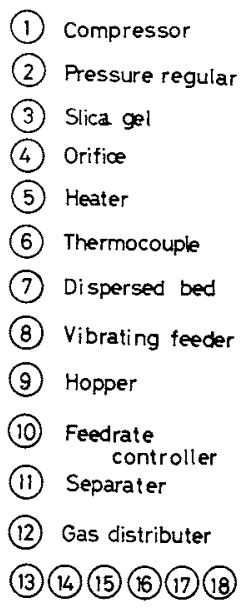

Ball valve
In this study, wet particles of activated alumina were dried by hot air in the constant drying rate period in a dispersed bed, and gas-particle heat transfer coefficients were measured. The effect of gas velocity, void fraction, particle diameter and bed height upon the gas-particle heat transfer coefficient were investigated.

\section{Experimental Apparatus and Procedure}

A schematic diagram of the experimental apparatus is shown in Fig. 1. The main part of the apparatus consisted of a cylindrical column made of polycarbonate or acrylic resins. Three different columns were used. Their dimensions were $10.5 \mathrm{~cm}$ inside diameter and $60 \mathrm{~cm}$ height, $7.7 \mathrm{~cm}$ inside diameter and $40 \mathrm{~cm}$ height, and $5.2 \mathrm{~cm}$ inside diameter and $40 \mathrm{~cm}$ height.

Air from a compressor was passed through a dehydration tower filled with silica gel, and its flow rate was measured by an orifice meter. The air was heated to a constant temperature by an electric heater and fed to the column through the distributor. So as to neglect sensible heat of the feed particles, the inlet air temperature of the column was chosen so that the wet-bulb temperature of the particles was equal to room temperature. The temperature distribution across the bed was measured by section chromel-alumel thermocouples with $3 \mathrm{~mm}$ I.D. ceramic tube placed at 5-cm intervals above the gas distributor. In drying the particles in the constant-rate drying period, their moisture content was found to be much higher than the critical moisture content. The particles and air flowed countercurrently through the bed.

Open-end cylindrical screen packings with $3.61 \mathrm{~cm}$ equivalent diameter were packed in the column to disperse the particles and gas well. The heating towers and the tube between the column and the heating towers were covered with asbestos as thermal in-
Table 1. Properties of activated alumina particles and screen packing size

Properties of activated alumina

\begin{tabular}{cccc}
\hline $\begin{array}{c}\text { Activated } \\
\text { alumina }\end{array}$ & $\begin{array}{c}D_{p} \\
{[\mathrm{~cm}]}\end{array}$ & $\begin{array}{c}\rho_{p} \\
{\left[\mathrm{~g} / \mathrm{cm}^{3}\right]}\end{array}$ & $\begin{array}{c}\phi_{s} \\
{[-]}\end{array}$ \\
\hline & 0.08316 & & \\
0.05271 & 0.9 & 1.0 \\
0.04805 & & \\
& 0.03165 & & \\
\hline
\end{tabular}

Screen packing

\begin{tabular}{llcccc}
\hline $\begin{array}{c}\text { Cylindrical } \\
\text { screen } \\
\text { packing }\end{array}$ & Sign & $\begin{array}{c}d \\
{[\mathrm{~cm}]}\end{array}$ & $\begin{array}{c}h_{c} \\
{[\mathrm{~cm}]}\end{array}$ & $\begin{array}{c}D_{p}{ }^{*} \\
{[\mathrm{~cm}]}\end{array}$ & $\begin{array}{c}\varepsilon_{b} \\
{[-]}\end{array}$ \\
\hline & PN-7 & 2.73 & 4.22 & 3.61 & 0.990 \\
\hline
\end{tabular}

sulator to minimize heat loss.

The experimental procedure was as follows. After the moisture content of feed particles was measured, the particles were fed to the bed at constant feed rate by a vibrating feeder and contacted countercurrently with hot dry air at constant flow rate. When the bed reached steady state, the temperature distribution across the bed and the particle feed rate were measured. The particle hold-up in the bed was also measured by shutting the air and particle flow suddenly by the ball values. The operation range was as follows. Superficial gas velocity was in the range of 10 to $120 \mathrm{~cm} / \mathrm{s}$, the inlet gas temperature was in the range of 308 to $368 \mathrm{~K}$, the temperature of feed particles was in the range of 287 to $308 \mathrm{~K}$ and the feed rate of the particles was in the range of 80 to 3480 g-dry solid/ min.

The properties of the activated alumina particles and the packing size used in these experiments are shown in Table 1. 
In the calculation of gas-particle heat transfer coefficient in the dispersed bed, the following assumptions are made.

1. The evaporation of water from particles is assumed to occur in a constant drying rate period.

2. The temperature of particles in the bed is the wet-bulb temperature $t_{w}$ of inlet gas.

3. In calculation of the particle Reynolds number, the average relative velocity of particles $\left(U_{p}+U_{G}\right)$ is used.

A heat balance across the whole bed gives

$$
Q=G_{0} C_{H}\left(T_{1}-T_{2}\right)=h a A L \frac{\left(T_{1}-T_{2}\right)}{T_{1}-t_{w}}+q_{\text {loss }}
$$

where

$$
q_{\mathrm{loss}}=U \pi D_{T} L \frac{\left(T_{1}-T_{2}\right)}{\ln \frac{T_{1}-t_{L}}{T_{2}-t_{L}}}
$$

The heat transfer coefficient from wall $h_{L}$ in Eq. (2) was calculated from Eqs. (1) and (2) in the case where the particles are not fed to the bed. If the mass velocity of air $G_{o}$, and inlet and outlet temperatures $T_{1}$ and $T_{2}$ are measured, the heat capacity coefficient $h a$ is calculated by Eqs. (1) and (2). The void fraction of particles is calculated from the particles hold-up. The specific surface area of particles is calculated as

$$
a=\frac{6(1-\varepsilon)}{\phi_{s} D_{p}}
$$

Therefore, the heat transfer coefficient $h$ is obtained from Eqs. (1) and (2). The average particle falling velocity in the bed $\bar{U}_{p}$ is given by

$$
\bar{U}_{p}=\frac{L}{\theta}=\frac{w_{0}}{\rho_{p} A(1-\varepsilon)}
$$

If the particle feed rate $w_{0}$ and void fraction $\varepsilon$ are measured, the particle falling velocity $\bar{U}_{p}$ is calculated from Eq. (4). From assumption 3, the particle Reynolds number is given by

$$
\operatorname{Re} p=\frac{\rho_{G}\left(U_{G}+\bar{U}_{p}\right) D_{p}}{\mu_{G}}
$$

\section{Experimental Results}

Figure 2 shows the radial temperature distributions. From Fig. 2, the temperature distribution is almost flat, but when the particles flow through the column, the temperature of gas decreases remarkably by heat transfer to the particles. The heat transfer coefficient between gas and particles was calculated by the average temperature in each cross section.

It is considered that the gas-particle heat transfer coefficient in the dispersed bed may be affected by gas velocity $U_{G}$, particle diameter $D_{p}$, void fraction $\varepsilon$, bed

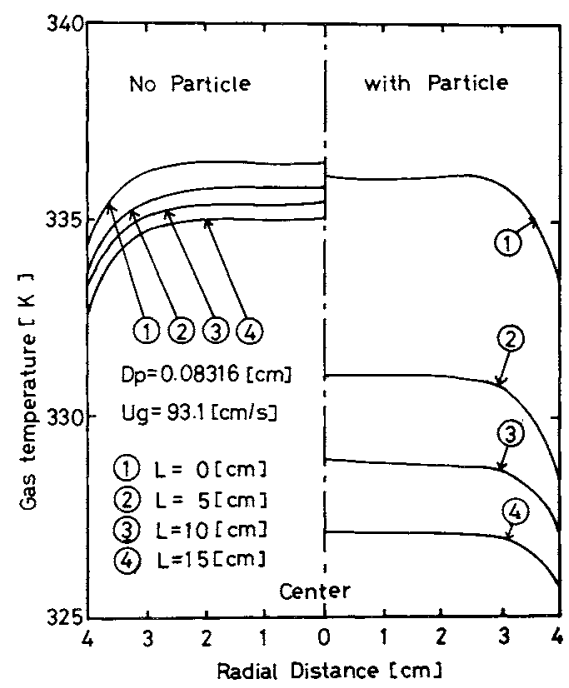

Fig. 2. Radial temperature distribution.

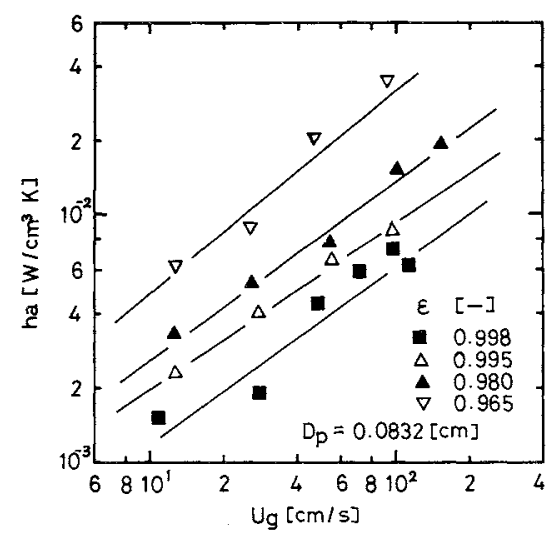

Fig. 3. Relation between $h a$ and $U_{g}$.

height $L$, and bed diameter $D_{t}$. Figure 3 shows the relationship between the heat capacity coefficient $h a$ and the superficial velocity $U_{G}$ with void fraction $\varepsilon$ as a parameter. The heat capacity coefficient decreases with increasing void fraction. Figure 4 shows the effect of the void fraction in the bed on the heat transfer coefficient. From Fig. 4, the heat transfer coefficient increases with increasing void fraction in the bed. Moreover, the heat transfer coefficient between gas and particles was unaffected by bed diameter and bed height.

From the above results, the Nusselt number may be affected by the particle Reynolds number as well as by the void ratio $\varepsilon /(1-\varepsilon)$. Figure 5 shows the relationship between the Nusselt number and $\varepsilon /(1-\varepsilon)$ with the Reynolds number as a parameter. From Fig. 5, the Nusselt number increases with increase of $\varepsilon /(1-\varepsilon)$. Figure 6 shows the relationship between the Nusselt number and the particle Reynolds number with $\varepsilon /(1-\varepsilon)$ as a parameter. From Fig. 6, the Nusselt number increases with increasing particle Reynolds number. The Nusselt number also increases with increasing void fraction. Moreover, when the void 


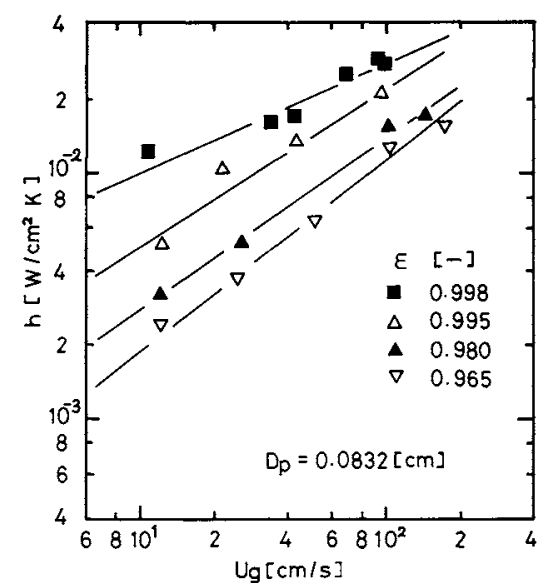

Fig. 4. Relation between $h$ and $U_{g}$.

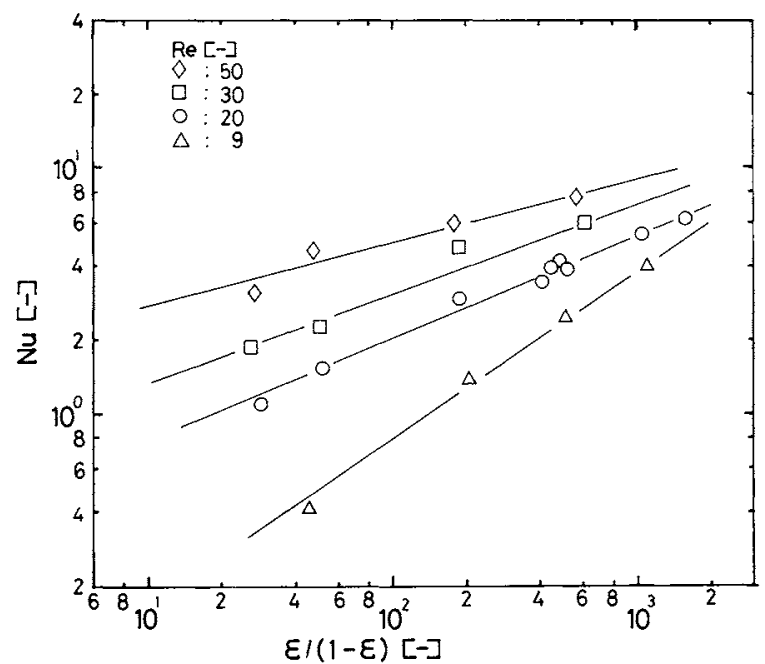

Fig. 5. Relation between $N u$ and $\varepsilon /(1-\varepsilon)$.

fraction is very close to 1 , the Nusselt number agrees approximately with the value calculated from the Ranz-Marshall ${ }^{1)}$ equation.

From these results the Nusselt number may be expressed as

$$
N u=\alpha \operatorname{Re} p^{n} \cdot\left(\frac{\varepsilon}{1-\varepsilon}\right)^{m}
$$

The power of the particle Reynolds number is the function of the void ratio $\varepsilon /(1-\varepsilon)$. From this experimental result, $n$ is expressed as

$$
n=2.48\left(\frac{\varepsilon}{1-\varepsilon}\right)^{-0.28}
$$

Figure 7 shows the relation between $N u /(\operatorname{Rep})^{n}$ and $\varepsilon /(1-\varepsilon)$. From Fig. 7, the following empirical equation for the Nusselt number in the dispersed bed is obtained as

$$
N u=2.38 \times 10^{-3}(\operatorname{Rep})^{n}\left(\frac{\varepsilon}{1-\varepsilon}\right)^{0.97}
$$

where

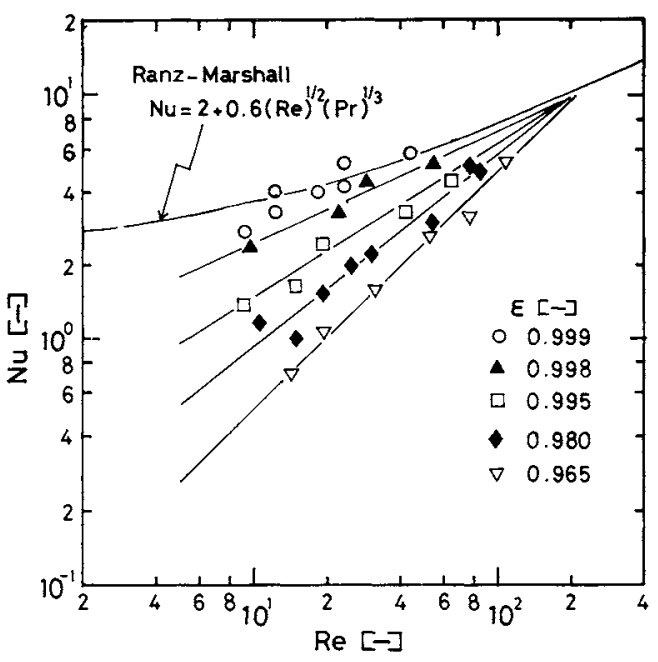

Fig. 6. Relation between $N u$ and $R e$.

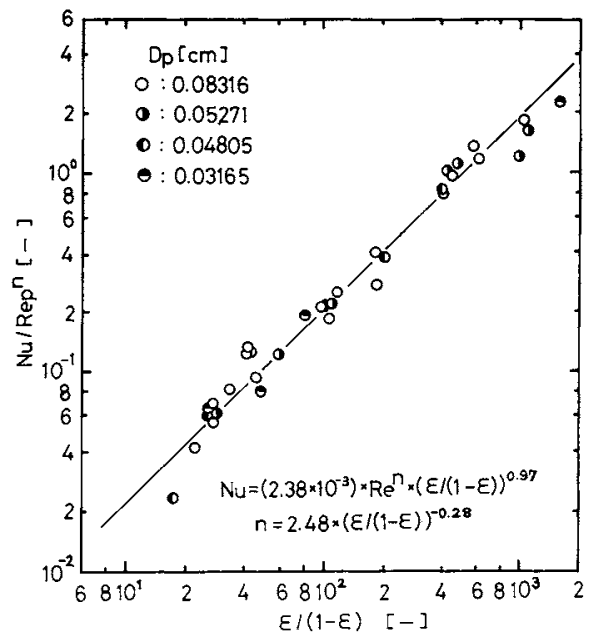

Fig. 7. Relation between $N u / R e^{n}$ and $\varepsilon /(1-\varepsilon)$.

$$
n=2.48\left(\frac{\varepsilon}{1-\varepsilon}\right)^{-0.28}
$$

The application ranges are as follows. The particle Reynolds number is in the range of 5 to 150 and void fraction is in the range of 0.94 to 0.999 .

\section{Discussion}

In these experiments open-end cylindrical screen packings were used to disperse the particles in the bed uniformly. When the void fraction is larger than 0.99 , the dispersion of particles was uniform without packings and gas-particle heat transfer coefficient without packings was equal to that with packings. However, when particle feed rate is large, the dispersion of particles in the bed without packings became nonuniform.

The particles were wetted in the range of 0.9 to $1.0 \mathrm{~g}$-water $/ \mathrm{g}$-dry solid. Even if the moisture content of each particle is not exactly uniform, the critical moisture content is lower than $0.5 \mathrm{~g}$-water/g-dry solid and most of the particles are dried in the constant 
drying period. No temperature rise of particles was observed in these experiments.

There are various interpretations for the reading of a suction thermocouple in fixed and fluidized beds. However, particle concentration in a dispersed bed is lean and the reading of the suction thermocouples shows gas temperature in the bed.

In Eq. (8), the power of the particle Reynolds number, $n$, increases with decreasing void fraction. The amount of particles per unit volume of bed increases with decreasing void fraction, and interference of gas films around the particles occurs. The interference effect between particles increases with decreasing superficial gas velocity, because the gas film increases with decreasing gas velocity. Consequently, no surface areas of the particles act as effective surface area for heat transfer. From Fig. 6, when the void fraction is about one the experimental Nusselt number approximately agrees with the calculated value from the Ranz-Marshall equation.

Heat loss from the bed wall was usually less than $5 \%$ of the heat transfer from gas to particles. The maximum heat loss was about $10 \%$. The effect of heat loss on the calculation of the gas-particle heat transfer coefficient by Eq. (1) is small.

\begin{tabular}{|c|c|c|}
\hline \multicolumn{3}{|c|}{ Nomenclature } \\
\hline A & $=$ cross-sectional area of bed & {$\left[\mathrm{cm}^{2}\right]$} \\
\hline$a$ & $\begin{aligned}= & \text { specific surface of particles per unit } \\
& \text { volume of bed }\end{aligned}$ & {$\left[\mathrm{cm}^{-1}\right]$} \\
\hline$C_{H}$ & $=$ humid heat & $\mathrm{J} / \mathrm{g}$-dry gas $\cdot \mathrm{K}]$ \\
\hline$D_{p}$ & $=$ particle diameter & {$[\mathrm{cm}]$} \\
\hline
\end{tabular}

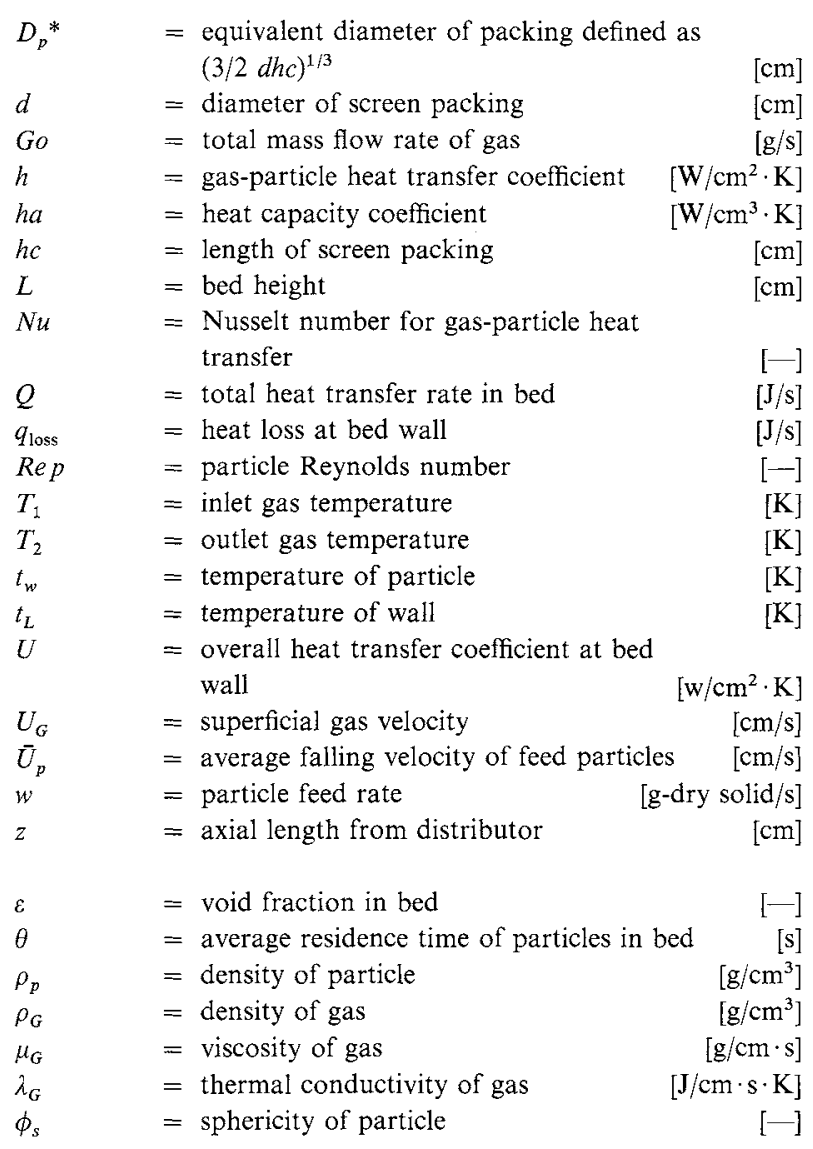

\section{Literature Cited}

1) Ranz W. E. and W. R. Marshall, Jr.: Chem. Eng. Progr., 48, 141 (1952).

(Presented at 47th Annual Meeting of The Society of Chemical Engineers, Japan at Tokyo, March, 1982.)

\title{
RECOVERY OF HEAVY SPECIES BY PULSE GAS DIFFUSION
}

\author{
NORIAKI WAKAO AND SHIGEHARU TANISHO \\ Department of Chemical Engineering, Yokohama National University, Yokohama 240
}

\begin{abstract}
Theoretical calculations were carried out for the separation of light and heavy species in a gaseous mixture. It is shown that a heavy species present in low concentration in a gas is effectively enriched by a batchwise diffusion unit in which the gas is imposed a number of times as a pulse on a porous separating membrane.
\end{abstract}

\section{Introduction}

The objective of this work is, as an extension of the earlier work, ${ }^{1-3)}$ to show with theoretically calculated

\footnotetext{
Received July 3, 1982. Correspondence concerning this article should be addressed to N. Wakao.
}

data that the unsteady-state diffusion process may be successfully employed with a batchwise diffusion unit to enrich a heavier species present in low concentration in a gaseous mixture.

The conditions underlying this diffusion process are that the diffusion should be of Knudsen type and a 